\title{
Study of the Form of Minerals in Copper Porphyry Ores of «Yoshlik-I» Deposit
}

\author{
Inoyat Umarova ${ }^{1}$, Sokhibjon Matkarimov ${ }^{*^{*}}$, Javlon Bekpulatov ${ }^{1}$, Dilmurod \\ Makhmaredjabov ${ }^{1}$, and Sherzod Yuldashev ${ }^{1}$ \\ ${ }^{1}$ Department of Mining and Metallurgy, Tashkent State Technical University, 100095 Tashkent, \\ Uzbekistan
}

\begin{abstract}
The purpose of these studies is to study the forms of finding copper-porphyry ores of the Yoshlik I deposit compared with the Kalmakyr deposit data and to decide on the choice of a cost-effective ore processing technology. As a result of the studies, it was revealed that ore mineralization is represented by sulfides of various metals and iron oxides. The primary sulfides are pyrite and chalcopyrite. In the "Yoshlik-I» sample, the pyrite content is six times less than in the Kalmakyr sample and is $0.7 \%$. The mass fraction of chalcopyrite in the Kalmakyr and «Yoshlik-I» deposits is 1.1 and $0.8 \%$, respectively. The remaining sulfides of various metals and the minerals of these ribs are present in several single signs. According to the content of cell fids, the Kalmakyr ore sample is characterized by a small-sulfide ore; the "Yoshlik-I» ore sample is a slab-sulfide type ore. According to the oxidation state calculated by iron, ore samples of the Kalmakyr and «Yoshlik-I» deposits belong to the mixed variety of ores.
\end{abstract}

\section{Introduction}

Uzbekistan is rich in all types of minerals. More than 1,600 mineral deposits have been developed and registered on the state balance sheet of the republic, of which more than two hundred are these deposits of non-ferrous, noble, and rare metals. Their gradual involvement in operation contributes to the growth of the industrial potential of the republic [1].

Currently, the «Yoshlik-I» copper-porphyry deposit is under development. In turn, this requires survey work to study the material composition and determine effective technologies for processing the ores of this deposit.

The Almalyk Mining and Metallurgical Plant is a significant producer of copper in our republic, and the copper industry is one of the leading branches of non-ferrous metallurgy. Therefore, the analysis and study of existing copper ore processing technologies, their improvement, and adaptation for the conditions of new deposits in the Almalyk region are very urgent tasks [2-4].

\footnotetext{
* Corresponding author: sohibtm@gmail.com
} 
The purpose of these studies is to study the forms of copper-porphyry ores of the «YoshlikI» deposit compared to the data of the Kalmakyr deposit and to decide on the choice of a cost-effective ore processing technology [5-7].

\section{Methods}

Various reagents and laboratory installations, modern physical, physicochemical and chemical methods of analysis were used in carrying out the studies. Process samples were taken at the points specified in the sampling map using samplers. In the end, all models were weighed, dried, and their dry weight and weight fraction of solid were determined. The samples were separated according to the appropriate procedure.

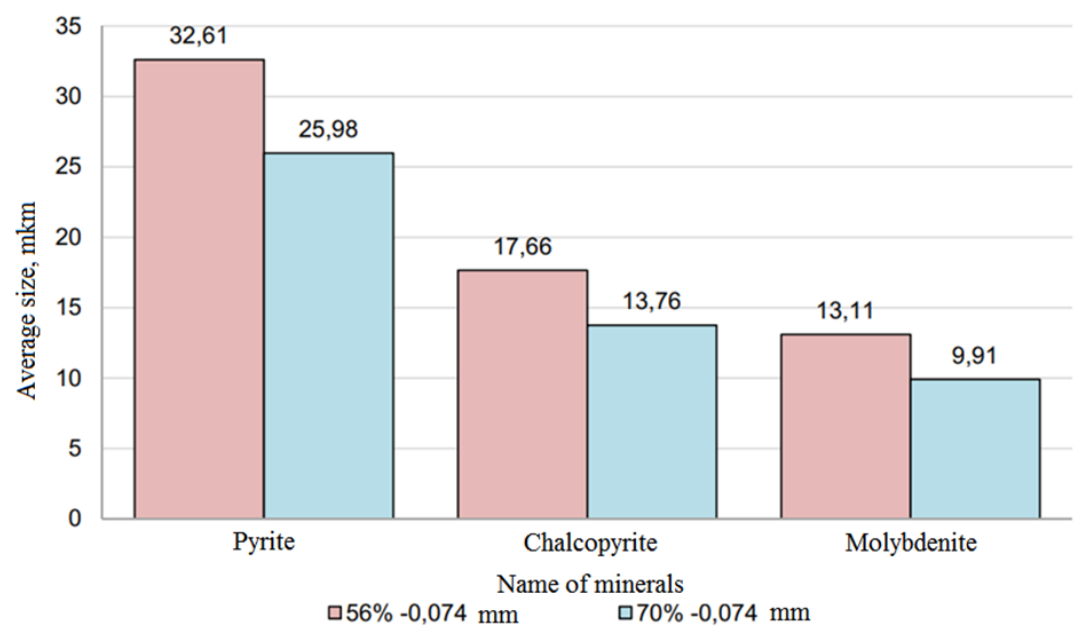

Fig. 1. The average grain size of the main ore minerals in the ore of the Kalmakyr deposit with a size of 56 and $70 \%$ of the class $-0.074 \mathrm{~mm}$

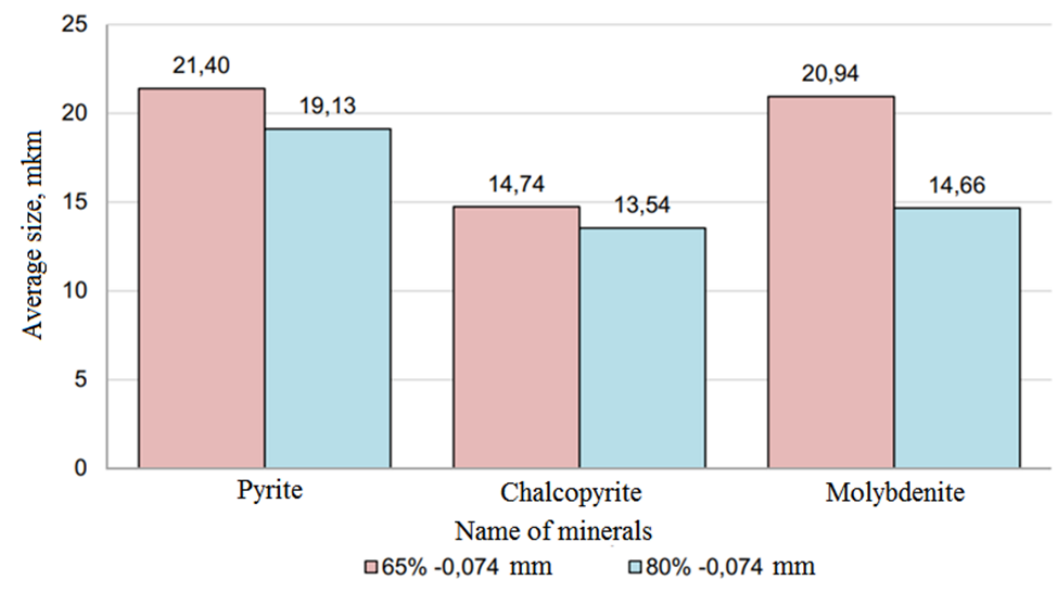

Fig. 2. The average grain size of the main ore minerals in the ore of the «Yoshlik-I» deposit with a length of 65 and $80 \%$ of the class $-0.074 \mathrm{~mm}$

The forms of ore minerals (chalcopyrite and molybdenite) in the Kalmakyr deposit ore sample were studied with a grinding size of 56 and $70 \%$ of the class $-0.074 \mathrm{~mm}$, the «Yoshlik-I» deposit ore at the height of 65 and $80 \%$ of the level $-0.074 \mathrm{~mm}$.

In all ore grinding samples, the average grain size of minerals is reduced. The average length of pyrite, chalcopyrite, and molybdenite, depending on the grinding size, varies in 
the following ranges: $19.13-32,61 \mathrm{mkm}, 13.54-17.66 \mu \mathrm{m}$ and $9.91-20.94 \mu \mathrm{m}$, respectively. The smallest average size of pyrite $-19.13 \mathrm{mcm}$ and chalcopyrite $-13.54 \mu \mathrm{m}$ was recorded in the «Yoshlik-I» sample with $80 \%$ of the class $-0.074 \mathrm{mcm}$, and molybdenite in Kalmakyr with a size of $70 \%$ of the class $-0.074 \mu \mathrm{m}[8-11]$.

Fig. 1 and 2 show the average dimensions of the main ore minerals with different ore grinding sizes.

The granulometric analysis of chalcopyrite in the ore samples of the Kalmakyr and «Yoshlik-I» deposits of various sizes are presented in Figures 3 and 4.

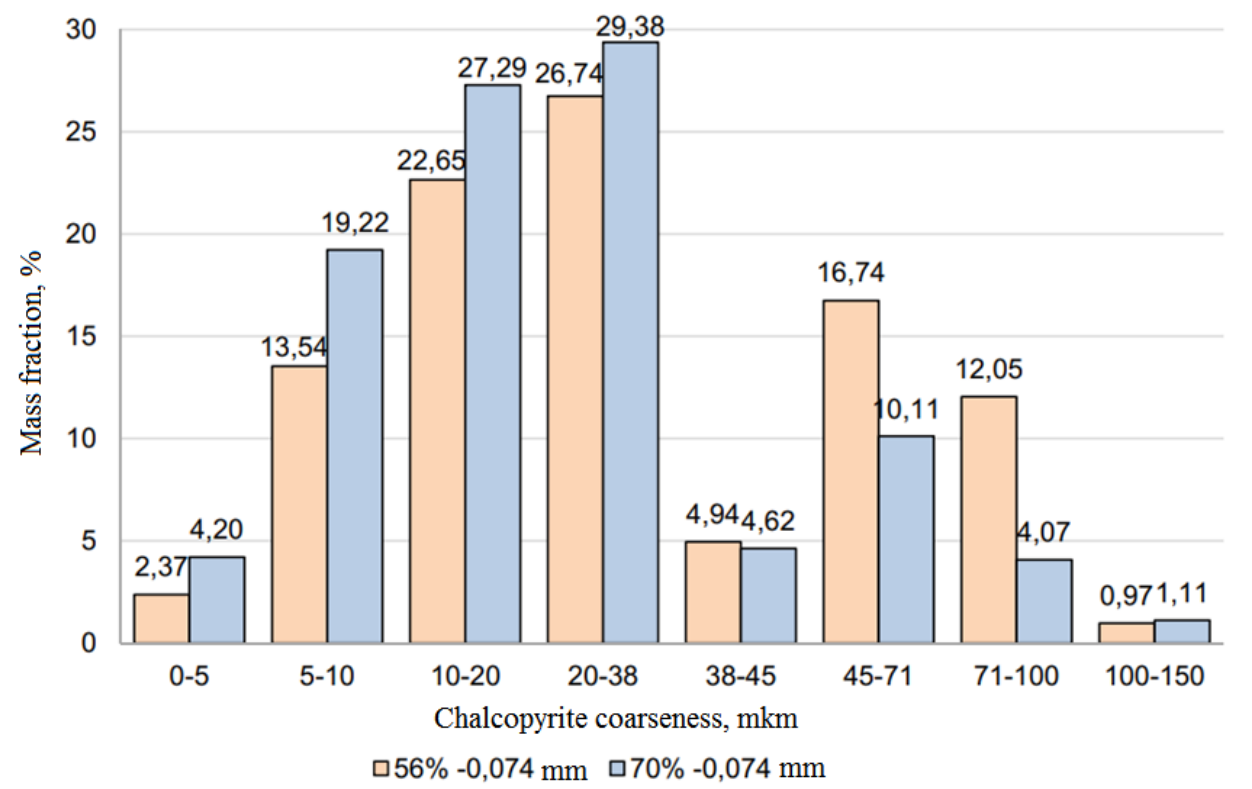

Fig. 3. Granulometric characteristic of chalcopyrite in a sample of ore of natural origin Kalmakyr

\section{Results and Discussions}

In samples of the Kalmakyr deposit ore, the bulk of chalcopyrite grains predominate in size classes of 5-38 microns. With the reduction of grinding tone from $56 \%$ to $70 \%$ of finished class, grain yield with a size of $5-38 \mathrm{mcm}$ increases from 62.9 to $75.9 \%$, mainly due to the reduction of grain fraction with $45-100 \mathrm{mcm}$. When the length of samples decreases, the mass fraction of sludge class less than five $\mu \mathrm{m}$ increases from 2.37 to $4.2 \%$.

In the ore samples of the «Yoshlik-I» deposit, most chalcopyrite grains are also in the size classes of 5-38 microns - $81.5 \%$ (for a size of $65 \%$ - 74 microns) and $82.9 \%$ (for a length of $80 \%-74$ microns). There is a decrease in grinding tone, mainly an increase in the size class of $5-10 \mu \mathrm{m}$ from 16.53 to $21.66 \%$. The weight fraction of the slurry class less than $5 \mu \mathrm{m}$ varies from 2.63 to $3.16 \%$ for different sizes.

It was established that in samples of ore of the "Yoshlik-I» and Kalmakyr deposits with a size of 65 and $70 \%$ of the $-74 \mu \mathrm{m}$ class, the share of chalcopyrite grains with an opening degree of less than $30 \%$ is 9.95 and $13.05 \%$, respectively. Since this category of chalcopyrite grains is the most resistant to flotation enrichment, it can be assumed that the extraction of copper from the ore of the «Yoshlik-I» deposits will be higher. In addition, in the «Yoshlik-I» sample, the number of free chalcopyrite grains is significantly higher (73.4\%). This fact indicates the possibility of obtaining a richer concentrate. 
Table 1 shows the mineral associations of chalcopyrite in the ores of the Kalmakyr and «Yoshlik-I» deposits.

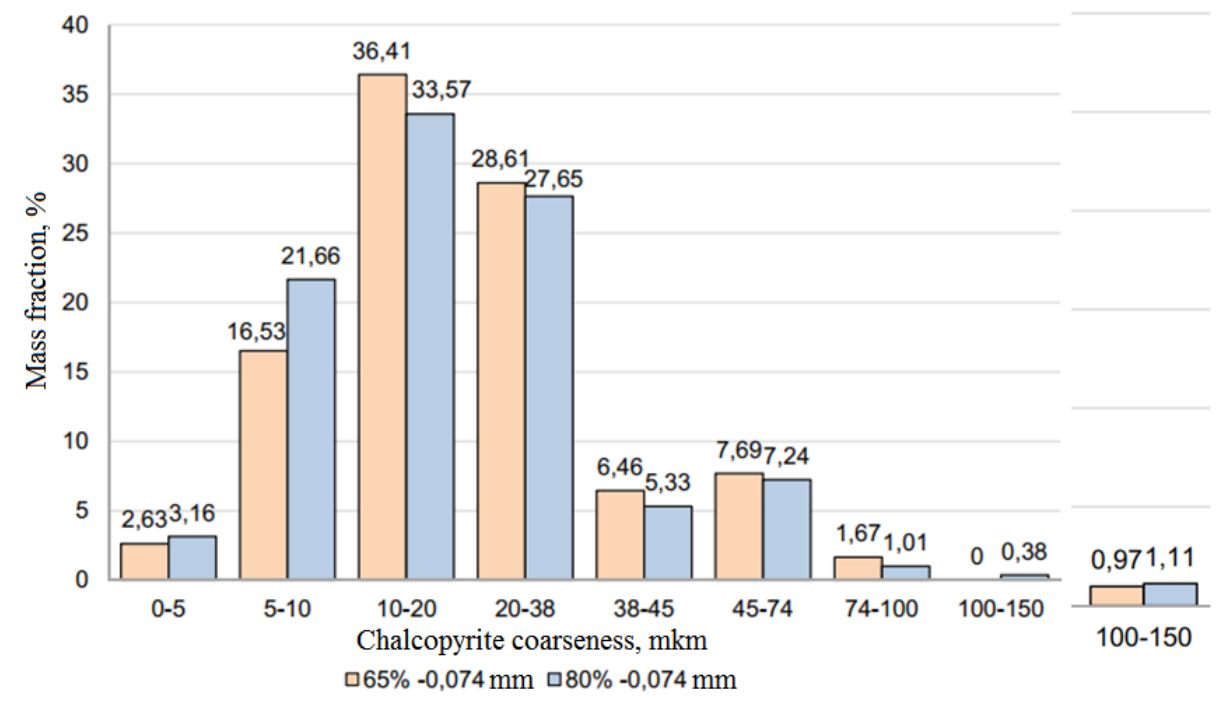

Fig. 4. Granulometric characteristic of chalcopyrite in the ore sample of the «Yoshlik-I» deposit

Table 1. Chalcopyrite Mineral Associations

Chalcopyrite distribution, $\%$

\begin{tabular}{ccccc}
\cline { 2 - 5 } $\begin{array}{c}\text { Mineral } \\
\text { carrier }\end{array}$ & \multicolumn{2}{c}{ Sample Kalmakyr } & \multicolumn{2}{c}{ Sample «Yoshlik-I» } \\
\cline { 2 - 5 } & $\begin{array}{c}\text { Size } 56 \%-0,074 \\
\mathrm{~mm}\end{array}$ & $\begin{array}{c}\text { Size } 70 \%-0,074 \\
\mathrm{~mm}\end{array}$ & $\begin{array}{c}\text { Size } 65 \%-0,074 \\
\mathrm{~mm}\end{array}$ & $\begin{array}{c}\text { Size } 80 \%-074 \\
\mathrm{~mm}\end{array}$ \\
\hline Background & 61.89 & 84.15 & 86.39 & 91.93 \\
\hline Quartz & 7.28 & 2.58 & 0.73 & 0.35 \\
\hline Chlorite & 8.15 & 3.77 & 1.67 & 0.64 \\
\hline Mica, clay & 8.66 & 4.05 & 2.12 & 1.52 \\
\hline Feldspar & 7.45 & 1.92 & 4.50 & 2.8 \\
\hline Amphiboles & - & - & 0.36 & 0.09 \\
\hline Carbonates & 0.77 & 0.42 & 0.31 & 0.38 \\
\hline Gypsum & - & - & 0.31 & 0.13 \\
\hline Pyrite & 2.56 & 1.42 & 2.29 & 1.29 \\
\hline Bornite & 0.44 & 0.22 & 0.23 & 0.11 \\
\hline Covellin chalcosine & 0.14 & 0.10 & 0.01 & 0.02 \\
\hline White ore & 0.04 & - & 0.01 & 0.03 \\
\hline Galenite & - & 0.03 & 0.11 & 0.16 \\
\hline Sphalerite & 0.10 & 0.12 & 0.05 & 0.01 \\
\hline Molybdenite & - & - & 0.02 & - \\
\hline Titanium minerals & 0.88 & 0.27 & 0.52 & 0.22 \\
\hline Oxides/Hydroxides & 1.22 & 0.80 & 0.27 & 0.23 \\
\hline Fe & 0.43 & 0.14 & 0.12 & 0.10 \\
\hline Accessory & 100.0 & 100.0 & 100.0 & 100.0 \\
\hline Total & & & & \\
\hline & & & & \\
\hline
\end{tabular}


The association of the mineral with the background indicates the proportion of the surface of the mineral to which reactants can freely access it.

According to data on mineral associations of chalcopyrite, it was found that from 61.89 to $91.93 \%$ of the mineral surface is available for solutions and reagents. The largest share of the disclosed surface of minerals is noted in the ore sample of the «Yoshlik-I» deposit with a size of $80 \%$ of the $-0.074 \mathrm{~mm}$ class. Chalcopyrite is mainly associated with rock-forming minerals: quartz, chlorite, mica, clay, etc. Of ore minerals, chalcopyrite associates mainly with pyrite.

The forms of molybdenite minerals in the Kalmakyr deposit ore sample were studied with a grinding size of 56 and $70 \%$ of the $-0.074 \mathrm{~mm}$ class, and the «Yoshlik-I» deposit ore with a length of $80 \%$ of the class $-0.074 \mathrm{~mm}$.

A grinding size of $56 \%-0.074 \mathrm{~mm}$, coarse-grained molybdenite up to 150 microns is present in the ore. When grinding ore to a length of $70 \%-0.074 \mathrm{~mm}$, molybdenite completely changes to a size of fewer than 38 microns. Mass fraction of molybdenite with size less than $38 \mu \mathrm{m}$ in ore with size $56 \%-0.074 \mathrm{~mm}$ is $72.2 \%$, for size $70 \%-0.074 \mathrm{~mm}$ $100 \%$.

Table 2. Molybdenite Mineral Associations

\begin{tabular}{cccc}
\hline & \multicolumn{3}{c}{ Molybdenite distribution,\% } \\
\cline { 2 - 4 } Mineral carrier & \multicolumn{2}{c}{ Sample Kalmakyr } & Sample «Yoshlik-I» \\
\cline { 2 - 4 } & $\begin{array}{c}\text { Size } 56 \%-0,074 \\
\mathrm{~mm}\end{array}$ & $\begin{array}{c}\text { Size } 70 \%-0,074 \\
\mathrm{~mm}\end{array}$ & Size $80 \%-0,074 \mathrm{~mm}$ \\
\hline Background & 84.41 & 97.81 & 98.5 \\
\hline Quartz & 10.60 & 0.30 & 0.87 \\
\hline Chlorite & 0.37 & 0.30 & 0.09 \\
\hline Mica & 3.92 & 1.21 & - \\
\hline Feldspar & 0.05 & 0.08 & - \\
\hline Carbonates & 0.16 & - & - \\
\hline Pyrite & 0.11 & - & - \\
\hline Chalcopyrite & - & 0.08 & - \\
\hline Titanium minerals & 0.21 & 0.08 & 0.08 \\
\hline Accessory & 0.05 & - & 100 \\
\hline Oxides/Hydroxides Fe & 0.11 & 0.15 & - \\
\hline Total & 100.0 & 100.0 & - \\
\hline
\end{tabular}

In the ore sample of the «Yoshlik-I» deposit, molybdenite grains are distributed unevenly and hopefully in size classes. Mass fraction of molybdenite grains of 5-74 mcm size varies from 12.99 to $28.75 \%$. The amount of refined grains of molybdenite with a size less than five $\mu \mathrm{m}$ is not more than $1.28 \%$. The maximum grain size is $74 \mu \mathrm{m}$.

It was established that in samples of the Kalmakyr deposit of different material sizes, the distribution of molybdenite by the degree of disclosure varies significantly. When crushed to $70 \%-0.074 \mathrm{~mm}$, the fraction of free grains reaches $83.32 \%$. With a $56 \%-0.074 \mathrm{~mm}$ size, this molybdenite is redistributed in the category of rich partially open and open splices. The ore sample of the «Yoshlik-I» deposit with finer grinding $(80 \%-0.074 \mathrm{~mm})$ increases the number of free grains of molybdenite to $92.57 \%$.

Table 2 shows the mineral associations of molybdenite in the ores of the Kalmakyr and «Yoshlik-I» deposits with different grinding sizes. The association of the mineral with the background indicates the proportion of the surface of the mineral to which reactants can freely access it. 
By data about mineral associations of molybdenite in test Kalmakyr, it is established that solutions and reagents at a fineness of $56 \%-0.074 \mathrm{~mm}$ are available to $84.41 \%$ of a surface of a mineral, at a refinement of $70 \%-0.074 \mathrm{~mm}$ this indicator is higher $-97.81 \%$. Molybdenite bulk at a fineness of 56\%-0.074 mm associates with quartz $-10.6 \%$. The small share of molybdenite is in joints with mica - 1.21-3.92\% — associates an insignificant amount of molybdenite with other minerals.

\section{Conclusions}

In the test, «Yoshlik-I» crushed to a fineness of $80 \%-74$ microns, $98.5 \%$ of a mineral surface area available to solutions and reagents. Mineral associations are presented by generally rock-forming minerals - in the sum of $1.41 \%$.

Thus, based on the conducted research, a mass fraction of copper in tests of ore of Kalmakyr and «Yoshlik-I» fields according to the sifter analysis - 0.49 and $0.34 \%$ respectively. According to granulometric characteristics, the gold content in tests of ore of Kalmakyr and «Yoshlik-I» fields was 0.87 and $0.38 \mathrm{~g} / \mathrm{t}$, respectively. In the test of ore of the Kalmakyr field, the content of iron and sulfur is according to $6.42 \%$ and $2.59 \%$. Litofil components present the chemical composition of $83.84-87.68 \%$ of ore of Kalmakyr and «Yoshlik-I» fields. The basic is silicon dioxide of 51.6-61.2\% and alumina of $13.7-15.29 \%$. Ore-forming elements are presented by iron and sulfur. The amount of iron is at the level of $5.12-6.45 \%$. Valuable components in tests are copper, molybdenum, gold and silver with the content of $0.3-0.41 \%, 0.0045-0.0054 \%, 0.34-0.84 \mathrm{~g} / \mathrm{t}$ and $1.5-2.35 \mathrm{~g} / \mathrm{t}$ respectively. The ore mineralization is presented by sulfides of various metals and oxides of iron. The main sulfides are pyrite and chalcopyrite. As this category of grains of chalcopyrite is the most persistent to floatation enrichment, it is possible to assume that extraction of copper from the ore of fields «Yoshlik-I» will be higher.

\section{References}

[1] N.A. Akhmedov, State and problems of technological researches of ores of Uzbekistan. Problems of processing of mineral raw materials of Uzbekistan. Materials of a republican scientific and technical seminar, (Tashkent, 2005).

[2] A.H. Hursanov, To the Almalyk mining and smelting plant - 70, The Mountain Bulletin of Uzbekistan 4 (79), (2019)

[3] A.A.Yusupkhodjaev, S.T. Khojiev, B.T. Berdiyarov, D.O. Yavkochiva, J.B. Ismailov, Technology of Processing Slags of Copper Production using Local Secondary Technogenic Formations, International Journal of Innovative Technology and Exploring Engineering 9(1), 5461-5472 (2019)

[4] S.T., Khojiev, S.T. Matkarimov, E.T.K. Narkulova, Z.T. Matkarimov, N.S. Yuldasheva, The technology for the reduction of metal oxides using waste polyethylene materials, METAL 2020 - 29th International Conference on Metallurgy and Materials 971-978. (2020)

[5] S.T. Matkarimov, Heat treatment processes of steel-smelting slags in the recovery environment, METAL 2020 - 29th International Conference on Metallurgy and Materials 105-112 (2020)

[6] S.T. Matkarimov, D.O. Yavkochiva, B.T. Berdiyarov, F.D. Nosirov, Hydrometallurgical processing of copper-smelting dust. Int. J. Emerging Trends in Engineering Research 8(7), 3088-3094 (2020)

[7] S.T. Matkarimov, B.T. Berdiyarov, Development of the Wasteless Technology of Processing of Steel-Smelting Slags. In: Karabegović I. (eds) New Technologies, 
Development and Application III. NT 2020. Lecture Notes in Networks and Systems, vol 128. (Springer, Cham. 2020)

[8] D.B. Kholikulov, S. Abdurahmonov, O.N. Boltaev, S.T. Matkarimov, Separation of metals from technological solutions copper production, Int. J. Emerging Trends in Engineering Research 8(7), 3557-3561 (2020)

[9] S.T. Matkarimov, B.T. Berdiyarov, A.A. Yusupkhodjayev, Technological parameters of the process of producing metallized iron concentrates from poor raw material, Int. J. Innovative Technology and Exploring Engineering 8(11), 600-603 (2019)

[10] I.K. Umarova, S.T. Matkarimov, Development of technology of floatation enrichment of gold-bearing ores of the Amantaytau field, Enrichment of Ores 2 29-33 (2020)

[11] S. Jacques, C.J. Greet, D. Bastin, Oxidative weathering of a copper sulfide ore and its influence on pulp chemistry and flotation, Minerals Engineering 99, 52-59 (2016) 